\title{
Effects of fault movement and material properties on deformation and stress fields of Tibetan Plateau*
}

\author{
Yong Zheng ${ }^{1, \uparrow}$ Xiong Xiong ${ }^{1} \quad$ Yong Chen $^{2}$ and Bin Shan ${ }^{1}$ \\ ${ }^{1}$ Key Laboratory of Dynamic Geodesy, Institute of Geodesy and Geophysics, Chinese Academy \\ of Sciences, Wuhan 430077, China \\ ${ }^{2}$ Institute of Geophysics, China Earthquake Administration, Beijing 100081, China
}

\begin{abstract}
We compare the factors which affect the movement of Tibetan Plateau by building three types of finite element models: an elastic materials (M-EC), a continuous model composed by non-linear materials (M-PC), and an elastic model with discontinuous fault movements (M-ET). Both in M-ET and M-EC, the materials in Qiangtang and Lhasa block are elastic, and in M-ET, discontinuous movement of faults is considered for evaluating the effects of strike-slip faults. In model M-PC Druker-Prager plastic materials are used in Qiangtang and Lhasa block. Comparisons of the numerical simulation and the GPS observations show following characteristics: (1) Under present tectonic environment, short-term deformation of Tibetan Plateau can be simulated well by elastic models; (2) Discontinuous fault activities increase the lateral extrusion of the eastern part of Tibetan Plateau, reduce the stress field level in Qiangtang, Tarim and Qaidam blocks and strengthen the E-W extensional force in the east and the west parts of Qiangtang block; (3) Properties of plastic materials reduce the total stress field and the E-W extensional force, thus, the normal fault earthquakes in southern Tibet is mainly owed to the effect of active fault movement. Based on the numerical simulations we speculate that faults movement may play a more important role on the kinematic pattern of Tibetan Plateau than bulk properties.
\end{abstract}

Key words: material properties; discontinuous fault; stress field; deformation

CLC number: P315.72 5 Document code: A

\section{Introduction}

As the collision zone of Eurasian Plate and Indian Plate, Tibetan Plateau is one of the most active tectonic places in the world. Its dynamic and kinematical processes are very important in research on continental tectonics (e.g, Peltzer and Tapponnier, 1988; Peltzer et al., 1989; Houseman and England, 1996; Royden, 1996; Royden and Burchfiel, 1997; Kong and Bird, 1996; Molnar and Tapponnier, 1975; Zheng et al., 2006, 2007; Fu et al., 1999). Since the beginning of the collision between Indian and Eurasian plates, Tibetan Plateau has been shortened more than $1400 \mathrm{~km}$ (Yin and Harrison,

\footnotetext{
* Received 21 January 2011; accepted in revised form 14 March 2011; published 10 April 2011.

† Corresponding author. e-mail: zhengyong@whigg.ac.cn

(C) The Seismological Society of China and Springer-Verlag Berlin Heidelberg 2011
}

2000) and uplifted about $4500 \mathrm{~m}$ (e.g, Molar and England, 1990, Molar et al., 1993). At present Indian Plate still moves at a speed of about $5 \mathrm{~cm} /$ a toward Tibetan Plateau (Wang et al., 2001), which produces seismic activities in Tibetan Plateau and its adjacent areas highly active. Since 2001, there are several big earthquakes occurred in this area, including the 2001 $M_{\mathrm{S}} 8.1$ Kunlun earthquake (Lin et al., 2001) and the 2008 Wenchuan, Sichuan earthquake (Stone, 2008). Especially Wenchuan earthquake, a thrust earthquake ruptured along the Longmengshan fault at the boundary of Tibetan Plateau and Sichuan Basin, killed more than 69000 people (Reported by Chinese government). So the tectonic environment and the geological settings are of critical importance for studying the dynamic process and the seismic activities of Tibetan Plateau.

Among the mechanisms which may be responsible for these geological phenomena, two factors are very 
important. The first one is material properties. During the process of collision between Indian and Eurasian plates, Tibetan Plateau has merged many micro tectonic blocks. Geological investigations, seismological detections and other kinds of observations all prove that materials in different tectonic blocks are quite different. For example, the crustal thickness of Qiangtang is about $70 \mathrm{~km}$, the material is quite weak and easier to flow, but material in Tarim Basin is quite strong and hard to deform (Yao et al., 2006, 2008). Such significant difference may be responsible for the different deformation and movement patterns of different blocks. In addition, material properties might act obviously differently in different time scales. For long time scale deformation, Royden et al. (1997) and Shen et al. (2001a) demonstrated that the crustal viscosity structure may control the evolution process of Tibetan Plateau. While in short time scale (say, in an earthquake cycle), the deformation pattern can be well simulated by elastic models (Xiong et al., 2003). Using data from geodetic measurements, geological surveys and seismological detections, Flesch et al. (2001) found the effective viscosities of Tibetan Plateau and the surrounding areas are about 10 times difference and in the lower crust there is a weak zone which makes it possible for eastward extrusion. So evaluation of the material effect is quite important for us to understand the present deformation and stress fields.

The other important factor is fault movements. There are some deep and active faults at the boundary of different blocks. GPS observations show that large amount of crustal materials flow out from Tibetan Plateau along strike-slip faults (Wang, et al., 2001). For this reason Monlar and Tapponnier (1975) proposed a lateral extrusion hypothesis. In this hypothesis most of the shortening of Tibetan Plateau caused by indention of Indian plate has been absorbed by strike slip along several major faults (e.g, Avouac and Tapponnier, 1993; Peltzer et al., 1989; Tapponnier and Monlar, 1977; Tapponnier et al., 2001; England and Monlar, 1990). Although there is a consensus that whether the distributed thickening (e.g, Houseman and England, 1993) or the lateral extrusion is the main mechanism for the shorten of Tibetan Plateau, the effect of active faults definitely plays an important role in the evolution process of Tibetan Plateau (Tapponnier and Molnar, 1979; Tapponnier et al., 1986, 1990; Peltzer and Saucier, 1996; Wang, 2001).

Although both the two factors are very important to the deformation and stress field of Tibetan Plateau, their effects are not the same. Thus, the difference be- tween the two types of effects is needed to be studied. Previously a mass of work has been done on this problem, however, some problems still need to be solved. One of them is about the discrete movement effect of the fault. In most part of the previous works the fault usually is regarded as a weak zone instead of a discontinuous boundary between two tectonic units. In this article we compare the difference of the effects of the two factors and simulate the fault zones as discontinuous contact surfaces, and then evaluate their relative importance on present stress filed and movement pattern of Tibetan Plateau.

\section{Geological environment}

Tibetan Plateau is uplifted by merging of a series of micro tectonic blocks, Since Palaeozoic era a lot of deep and long active faults and big fold belts have been generated throughout the Tibetan Plateau, including Lhasa, Himalaya, Qiangtang, Tarim, Tianshan, Songpan-Ganzi, Qaidam blocks and Karakorum-Jiali, Western Kunlun, Eastern Kunlun, Xianshuihe-Honghe River, Altyn Tagh faults. All of the major blocks and big faults are shown in Figure 1.

In order to build a mechanic model for Tibetan Plateau, we outline the tectonic structures based on the geological characteristics. The movement and tectonics of Lhasa terrane and Himalayan collision belt are quite similar, so we merged them into a whole tectonic block called Tibet Block. Tibet Block and Qiangtang Block are separated by Jiali fault so we set them as independent blocks. Since the Qaidam Basin, the Qiangtang and the Songpan-Ganzi Block are also separated by active faults, we also set them as independent blocks. In order to analyze the effect of discontinuous fault movement, we simulate the major faults both as continuous belt and discontinuous fault. However, since there is no obvious slip rate between the two sides of the Tianshan mountain, we set it as a continuous belt in all of our numerical models.

\section{Theory and numerical models}

\subsection{Theory of stress field and deformation}

The stress field of Tibetan Plateau is analyzed based on the assumption that the deformations between different blocks in Tibetan Plateau interact with each other by stress transmissions. The deformation fields between surrounding blocks are continuous or transmit from one block to another one under the controlling of 


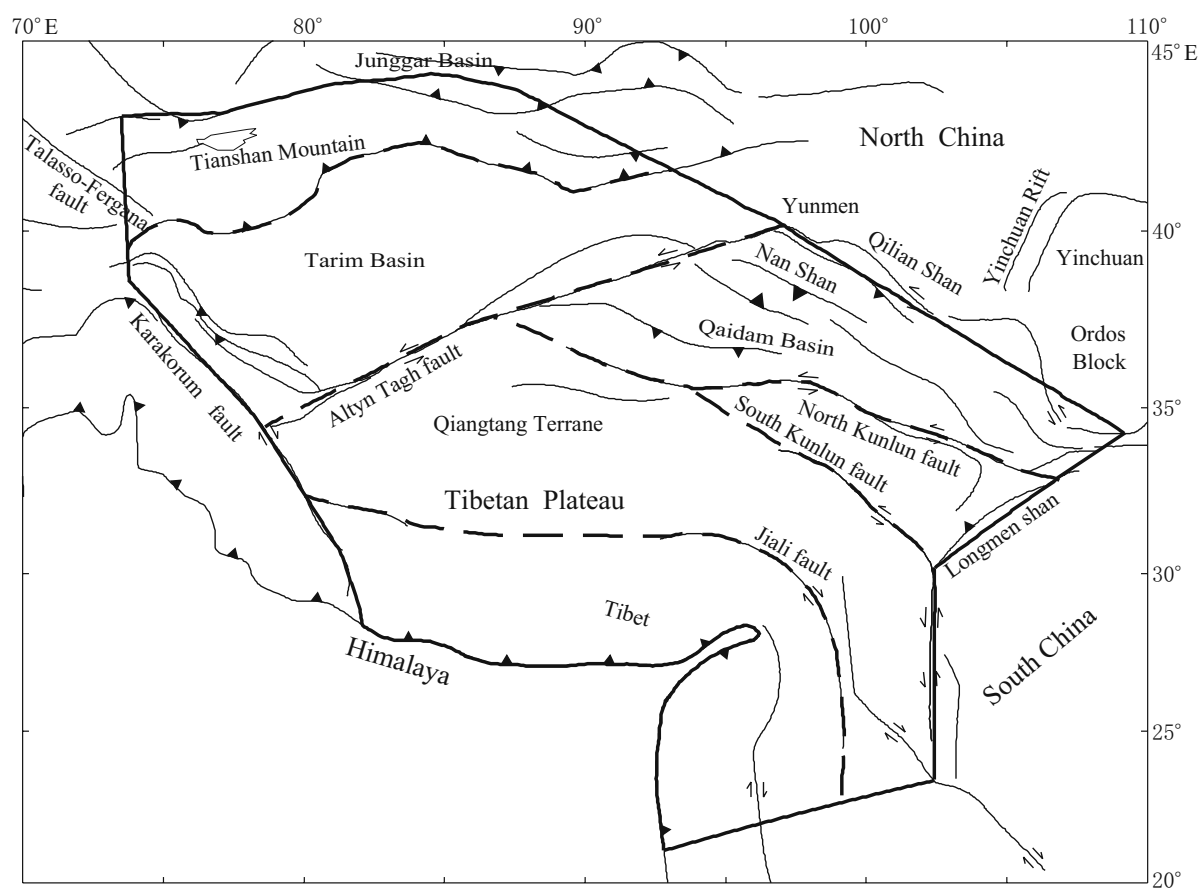

Figure 1 Tectonic settings of Tibetan Plateau and its surroundings. The thick black lines are the boundaries of the tectonic blocks. Among the thick lines, the solid thick lines outline the boundary of the numerical models in this work. The thick dash lines are the boundaries of the major tectonic blocks. The thin lines represent the Quaternary faults.

fault contact effects, the interior movement of one block is controlled by the continuity equation and force balance equation. In this paper, the static structure analysis is adopted. The controlling equations are

1) Force balance equation:

$$
\sigma_{i j, j}+\rho g a_{i}=0 .
$$

2) Stress-strain relationship

a) Elastic material:

$$
\sigma_{i j}=2 \mu \varepsilon_{i j}+\lambda \theta \delta_{i j},
$$

where, $\lambda=E \nu /(1+\nu)(1-2 \nu), \mu=E / 2(1+\nu), E=$ $\mu(3 \lambda+2 \mu) /(\lambda+\mu)$ is elastic modulus, $\nu=\lambda / 2(\mu+\lambda)$ is Poisson's ratio.

b) Drucker-Prager plastic material (D-P)

Equivalent force:

$$
\sigma_{\mathrm{e}}=3 \beta \sigma_{\mathrm{m}}+\left(\frac{1}{2} S_{i} M_{i j} S_{j}\right)^{1 / 2}
$$

Here $\sigma_{m}$ is the hydrostatic stress, which equals to $\left(\sigma_{x}+\sigma_{y}+\sigma_{z}\right) / 3, S_{i}$ is the deviatoric stress, $S_{i}=$ $\sigma_{i}-\sigma_{\mathrm{m}} \delta_{i}, i=1,2,3,4,5,6, \delta_{i}=\{1,1,1,0,0,0\}, M_{i j}$ is the diagonal matrix $\{1,1,1,2,2,2\}$

$$
\beta=\frac{2 \sin \phi}{\sqrt{3}(3-\sin \phi)},
$$

where $\phi$ is the angle of internal friction.

The material yield parameter is defined as

$$
\sigma_{\mathrm{y}}=\frac{6 c \cos \phi}{\sqrt{3}(3-\sin \phi)},
$$

where $c$ is the cohesion force. The yield criterion of D-P is described as

$$
\sigma_{\mathrm{e}}=\sigma_{\mathrm{y}}
$$

3) Contact force equations.

The relative movement between two sides of a fault can be looked as the contact movement between two contact surfaces. In general the materials in the two sides have no big difference, and the contact status always can not be known in advance (Ding et al., 2001), in this paper we adopt the "node to surface analysis", and take one side of the fault as target surface and the other side as contact node, and vice versa; then we generate the contact element by the contact pair. The fundamental parameters of contact pairs are contact stiffness, stick stiffness and friction coefficient. The contact force is computed by Pinball algorithm (ANASYS, Inc. Theory, Release 5.7 Version, 14-190 14-192). If the contact node penetrates the target plane, the contact force will be generated, the normal force can be expressed as 


$$
f_{\mathrm{n}}= \begin{cases}K_{\mathrm{n}} g & g \leq 0 \\ 0 & g>0\end{cases}
$$

Here, $K_{\mathrm{n}}$ is the contact stiffness, $g$ is the gap between the contact and the target surface. The tangential force can be expressed as

$$
f_{\mathrm{s}}=\left\{\begin{array}{cl}
K_{\mathrm{t}} u_{\mathrm{s}}^{\mathrm{e}}<F \bar{f}_{\mathrm{s}} & \text { Contact surface locked } \\
\bar{f}_{\mathrm{s}} & \text { slip on surface }
\end{array}\right.
$$

here $K_{\mathrm{t}}$ is tangent contact stiffness, $u_{\mathrm{s}}^{\mathrm{e}}$ is the contact slip distance, $\bar{f}_{\mathrm{s}}$ is friction force, $F$ is the ratio of static/slip friction ratio factor. Slip friction force is

$$
\bar{f}_{\mathrm{s}}=-\mu f_{\mathrm{n}},
$$

$\mu$ is slip friction coefficient, and $f_{n}$ is the normal force.

\subsection{Finite element models}

In order to study the effect of material propertie and discontinuous faults movement on the deformation and stress fields of Tibetan Plateau, we compare three kinds of models: continuous elastic model (M-EC), contact elastic model (M-ET) and continuous D-P plastic model (M-PC). As the spatial scale is not very large, rectangular coordinate system is applied in our work.

We build the geometrical models based on the real tectonic settings, and apply FEM method to solve them. The element grids are meshed as Figure 2. For continuous M-EC model and M-PC model, the solid thick lines are the boundaries of the model, the stress fields and the movements between the boundaries are continuous. For the discontinuous model (M-ET), the faults are set as discontinuous contact pairs except Tianshan Mountain, the stress fields and the movements across faults are discontinuous. In the FEM models, the interior of tectonic blocks are continuous, and the element type is triangle element. The biggest spatial length of the grid is $100 \mathrm{~km}$ and the smallest length is $10 \mathrm{~km}$.

For elastic models M-EC and M-ET, the element types and the materials of the tectonic blocks are the same. But for plastic model M-PC, the materials in Tibet Block and Qiangtang Block are different. In order to analyze the effect of anelastic material properties on the stress and deformation fields, we apply plastic material to simulating the behavior of Tibet Block and

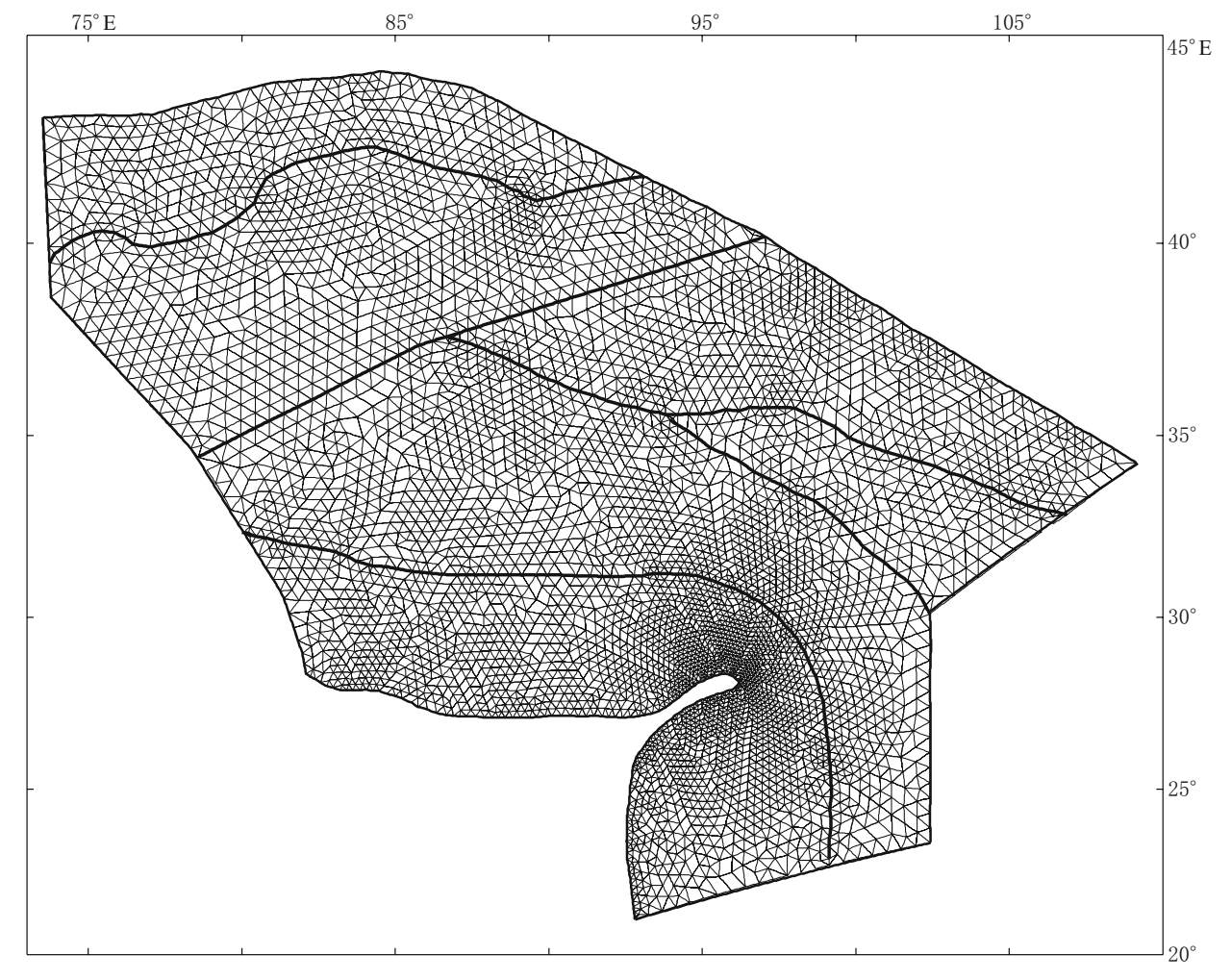

Figure 2 Mesh grids and finite elements of the numerical models. The thick lines are the boundaries of the tectonic blocks, in discontinuous model M-ET, all of the thick lines are discontinuous faults except Tianshan mountain. Their elements are modeled in CONTAC48 element, the element in the interior of the blocks are triangle Plane82 element (used in ANSYS). 
Qiangtang Block. The reason for selecting these two blocks is that these two blocks are the main body of Tibetan Plateau, and most of the thickening, crustal shortening and lateral extrusion happen in these areas. Furthermore, previous studies show that in these areas the materials are quite different from other regions (e.g., Liu and Yang, 2003; Flesch et al., 2001), and DruckerPrager plastic material is quit suitable for describing deformation in crust and lithosphere (Ding et al., 2001).

\subsection{Model parameters}

Based on the research on seismological prospecting and geological survey (Ding et al., 2001; Su et al., 2002), and by testing many sets of mechanic parameters, we finally chose the parameters in our FEM models as listed in Tables 1, 2 and 3.

Table 1 is the material properties and finite element parameters of continuous elastic model M-EC, Table 2 lists the parameters of D-P plastic materials used in Tibet and Qiangtang block, materials in other blocks are the same as that in Table 1 . Table 3 shows the stiffnesses and friction coefficients of the discontinuous faults.

Table 1 Mechanic parameters for continuous elastic model (M-EC)

\begin{tabular}{|c|c|c|c|c|c|c|}
\hline Block & $\begin{array}{c}\text { Elastic } \\
\text { Modulus } / 10^{10} \mathrm{~Pa}\end{array}$ & $\begin{array}{l}\text { Density } \\
/ \mathrm{kg} \cdot \mathrm{m}^{-3}\end{array}$ & $\begin{array}{l}\text { Poisson } \\
\text { ratio }\end{array}$ & $\begin{array}{l}\text { Element } \\
\text { number }\end{array}$ & $\begin{array}{l}\text { Element } \\
\text { type }\end{array}$ & $\begin{array}{l}\text { Node } \\
\text { number }\end{array}$ \\
\hline TIB & 6.5 & 2700 & 0.27 & 3795 & Plane82 & 7842 \\
\hline QTB & 4.5 & 2700 & 0.27 & 2285 & Plane82 & 4760 \\
\hline TAB & 8.5 & 2800 & 0.27 & 1261 & Plane82 & 2650 \\
\hline QAB & 6.5 & 2700 & 0.27 & 1191 & Plane82 & 1820 \\
\hline SGB & 6.5 & 2700 & 0.27 & 390 & Plane82 & 855 \\
\hline TSB & 6.5 & 2700 & 0.27 & 709 & Plane82 & 1532 \\
\hline
\end{tabular}

Note: In this table the full names of abbreviated labels are TIB: Tibet Block, QTB: Qiangtang Block, TAB: Tarim Block, QAB: Qaidam Block, SGB: Songpan-Ganzi Block, TSB: Tianshan Block.

Table 2 Mechanic parameters for continuous D-P plastic model (M-PC)

\begin{tabular}{cccccc}
\hline Block & Element number & Element type & Node number & $C / 10^{7}$ Pa & $\phi$ \\
\hline TIB & 3795 & Plane82 & 7842 & 1.8 & 30 \\
QTB & 2285 & Plane82 & 4760 & 1.5 & 30 \\
\hline
\end{tabular}

Note: In this table, TIB: Tibet Block, QTB: Qiangtang Block. $C$ is the cohension force, $\phi$ is the angle of internal friction.

Table 3 Parameters for contact elements

\begin{tabular}{lccc}
\hline Contact pair & $\begin{array}{c}\text { Friction } \\
\text { coefficient }\end{array}$ & $\begin{array}{c}\text { Normal } \\
\text { Stifness } / 10^{7} \mathrm{~Pa}\end{array}$ & $\begin{array}{c}\text { Tangential } \\
\text { Stifness } / 10^{6} \text { Pa }\end{array}$ \\
\hline Himalayan-Qiangtang & 0.4 & 4 & 1 \\
Qiangtang-Songpan & 0.3 & 5.2 & 5 \\
Qiangtang-Qaidam & 0.4 & 5.2 & 5 \\
Qiangtang-Tarim & 0.4 & 6 & 5 \\
Qaidam-Songpan & 0.5 & 5 & 4 \\
Tarim-Qaidam & 0.4 & 5.2 & 5 \\
\hline
\end{tabular}

\section{Numerical Results}

\subsection{Numerical strategy and process}

The GPS data (2001) are applied as the boundary conditions in our models. Because of the unevenly distribution of GPS stations, in areas with dense stations, we use interpolation method to make sure that each node on boundaries has velocity constraint. In areas with few station, REVEL model (Sella et al., 2002) is used as boundary conditions. In the boundary of western Myanmar there are very few observed data, furthermore the movement in this area is mainly along NS direction, the EW component velocity is very small. So the E-W movement is fixed and the movement in N-S direction is free in the west boundary of this region.

\subsection{Velocity fields}

We compute the velocity filed of the continuous elastic model (M-EC), continuous D-P plastic model 
(M-PC) and the discontinuous contact model (M-ET) under the boundary constraint by GPS observations. Then we compare them with the measurement results to analyze the effects of material and faults movement.

\subsubsection{Velocity field of M-EC model}

The simulated velocity field of M-EC model and the GPS observed velocity are compared in Figure3a. The simulated velocity field has no big difference from GPS observation, which is the evidence that in short time period, especially in GPS observation time (generally in a period of an earthquake cycle), elastic deformation is dominant in the total strain field. In continuous elastic model, there is no velocity abrupt change between neighboring blocks, the horizontal velocities decrease gradually from Tibet Block to the north part of the plateau. In the east part of the plateau, we can find that the crust movement gradually turns directions from $\mathrm{N}$ to $\mathrm{E}$ or SE.

In Tarim Basin, the simulated result of M-EC model is in good consistence with GPS observation, which may show that the deformation of Tarim Basin is mainly generated by elastic movement that is reasonable because geological research shows that Tarim Basin is very strong and hard to be deformed in anelastic way. For the same reason, in most part of Qaidam Basin, similar phenomenon occurs. However, there are some places where the simulated velocities are different from the GPS data. The first area locates in the east Tarim Basin, where the GPS stations are close to the Altyn Tagh fault and the elevation is much higher than that in the inner of the Tarim Basin. GPS observation shows that the directions of the surface movement are northwestward (Shen et al., 2001b), while the direction of simulated velocitie field ranges from $\mathrm{N}$ to $\mathrm{NE}$ (Figure 3a). There are two reasons for this kind of the difference, one is gravity potential effect. Because the elevation of Altyn Tagh fault is much higher than the interior of Tarim Basin, the gravity potential will change the movement direction from SE to NW, our model is a 2-D model and the gravity potential effect is neglected, so the difference is to be expected. The other reason may come from the discontinuous movement of Altyn Tagh fault, but the mechanism in detail is still unclear.

The second area is in the middle and east part of Qiangtang Block. In this place the eastward component of simulated velocity filed is smaller than that of GPS observation, the simulated velocity directions are dominated by $\mathrm{N}$ or $\mathrm{NE} 20^{\circ}$, which is about $10^{\circ}-20^{\circ}$ different from the observations. This deviation shows that the neglect of sinistral Kunlun fault in the M-EC model may reduce the eastward movement of crustal mass in east Tibetan Plateau.

\subsubsection{Velocity field of M-ET model}

In order to analyze the effects of active faults on Tibetan Plateau and its adjacent areas, we set Altyn Tagh fault, Jiali fault, Xianshuihe fault and Kunlun fault as discontinuous contact elements in M-ET model, and set the two sides of discontinuous fault as contact nodes and target surfaces, and then apply the contact parameters that listed in Table 3 to simulate the velocity field in this area.

Comparing the result of M-ET model with that of M-EC model (Figure 3b), we find that the predicted eastward velocity in Qiangtang Block of M-ET model is larger than that of M-EC, while in the middle part and the west part of Tibet Block the two velocity fields have no obvious difference. The eastward velocities between the two sides of Jiali fault have quite big difference, eastward velocity in the north side of Jiali fault is much larger than the south side, so in M-ET model Jiali fault is experiencing obvious right lateral strike-slip, this slip may strongly increase the trend of eastward flow of crustal mass in eastern Tibetan Plateau. In Xianshuihe fault and Altyn fault, similar phenomenon happens. The differences in the model M-ET and model M-EC mainly come from the existence of discontinuous faults. Because of the discontinuous strike-slip of Jiali fault and Kunlun fault, mass in Qiangtang Block can move more easily to the weak zones. Royden et al. (1997) demonstrated the eastern part of Tibetan Plateau is quite weak, the lower crust in this area may decouple from the upper crust, thus, provide a channel for lateral extrusion, so mass can move out from Qiangtang Block eastward or southeastward along Jiali and Xianshuihe faults. All of these differences show that fault slip may play an important role on the crustal and lithospheric deformation of Tibetan Plateau. But in the places far from faults, such as the northeast part of Qaidam Basin, Tian Shan Block, the movements of two models have little differences. This shows the effect of fault mainly concentrates in its near neighbors and takes little effect on far field.

\subsubsection{Velocity field of M-PC model}

M-PC model is used to analyze the anelastic material effect on Tibetan Plateau. We set the materials in Qiantang and Tibet Block as Druker-Prager plastic, and compare the predicted velocity field with that of M-EC and M-ET to discuss the relative importance of material effect and active faults effect.

Comparison shows the simulated velocity fields of 

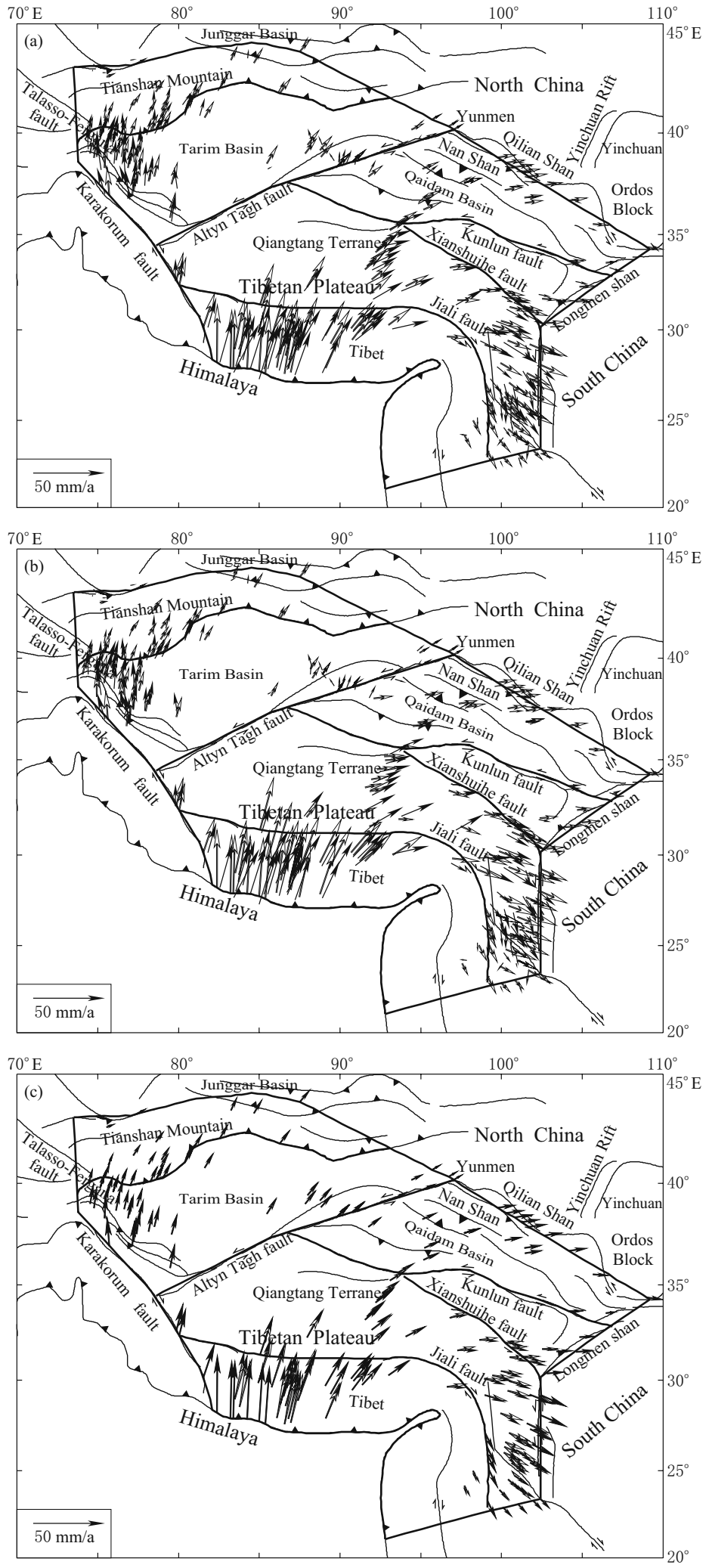

Figure 3 Simulated velocity fields of three models. (a) Comparison between velocity field of M-ET and GPS observation (Wang et al., 2001). The open arrows are the result of M-ET and the solid ones are the GPS velocities. (b) Comparison of velocity fields between M-EC and M-ET models. The open arrows show the result of M-ET and the solid ones are the velocities of M-EC. (c) Comparison of velocity fields between M-EC and M-PC models. The open arrows are the velocities of M-PC and the solid ones are the result of M-EC. 
M-EC and M-PC are almost the same (Figures 3a and 3c), this argues that most of the deformation in short time scale are elastic, we can analyze the transient kinematic process with elastic models. There are still small differences between M-EC and M-PC, which mostly locate in the eastern part of Qiangtang Block and Sichuan-Yunnan region. In these areas the eastward and southeastward velocity of M-PC model is smaller than that of M-EC model, which may implicit that the non-linear deformation absorbs the eastward movement, thus decreases the trend of mass moving out of Tibetan Plateau and thickens the crust of Qiangtang Block.

\subsection{Stress field}

Researching on stress field and its effects will help us understand the evolution process of orogens and the seismicity activities. Here we simulate the stress fields of three different models and discuss their relationships. Figure 4 shows the stress fields of the three models. One thing should be noted that anomalous high stress field may be found in some regions near the boundaries, most of them are artificial results because of boundary effect. So in this work we neglecte these areas.

\subsubsection{Simulated stress field of M-EC}

The predicted stress field of M-EC (Figure 4a) shows that the stress field of Tibetan Plateau changes gradually from south to north and varies evenly from west to east. There is no suddenly change between neighboring blocks. In Tibet Block the stress level is much higher than that in other blocks, the amplitudes of the stress field decrease from south to north. In the west part of Tibet Block, the stress field is composed of big northwest-southeast (NW-SE) compression and weak west-east or southwest-northeast (SW-NE) extension. The extensional force gets larger and larger from west to middle part of Tibet Block, in the east part of Tibet Block, the NW-SE compressionl forces get smaller and the SW-NE extensional forces get much larger and finally dominate near the east corner of Himalayan Mountain. Stress field of Qiangtang is similar to that of Tibet Block, but the stress field has no obvious changes from south to north. Stress field in the east part of Qiangtang Block where mass flows out of the plateau is basically controlled by near N-S extensions.

The stress field in Tarim Basin is mainly composed of N-S compression, and the stress amplitude is larger in the south boundary of the basin, this may be the reason that most deformation concentrates on the boundaries of Tarim Basin. In east Qaidam Basin the stress field is weaker than other blocks, while in the west part of
Qaidam Basin it is almost as big as Qiantang Block.

\subsubsection{Simulated stress field of M-ET}

The stress field on M-ET is quite different from MEC. Comparing Figures 4a and 4b, we can find following characteristics. (1) Tectonic forces in different tectonic blocks have larger differences in M-ET than in M-EC. The big stress field areas mostly concentrate in Qiangtang Block and Tibet Block. In Tarim basin, Qaidam Basin and Tianshan Block, the stress fields are so weak that it can be neglected in the figure. This means that the existence of active faults, such as Altyn Tagh fault and Kunlun fault strongly decreases the stress level in the north part of the model. Besides, stress field in Qiangtang Block is also decreased by the active faults. Our result is different from the previous work (Zheng et al., 2007), which may be caused by some modifications on the boundary conditions. (2) In contact model (M-ET), the stress field is dominated by E-W extensional force, in Tibet Block and west part of Qiangtang Block this pattern is more obvious. This kind of stress field is more close to the tectonic background, which means that the fault effect is a very important factor for formation of the extensional rift structure system in the south part of Tibetan Plateau, although other kinds of mechanisms, such as topography, small scale mantle convection are also important. Because of the existence of Jiali fault, the driving force of Indian Plate turns from north to east, which makes crustal materials of eastern Tibet move eastward along the dextral Jiali fault. At the same time, the right lateral strike-slip movement of the fault increases the eastward extrusion of Tibetan Plateau and further enhances the extensional stress in this region. Our simulation result of M-ET is quite close to Xu et al. (1989)'s seismological research and the result of Flesch et al. (2001) by GPS fitting method.

\subsubsection{Simulated stress field of M-PC}

Comparing Figures $4 \mathrm{a}, 4 \mathrm{~b}$ and $4 \mathrm{c}$, we can see that the stress field of model M-PC is neither close to M-EC nor close to M-ET. Following characteristics can be observed in M-PC. (1) The stress level of Tibetan Plateau is lower than that of M-EC, especially in Qiangtang and Tibet Block. But for other areas, such as Tarim and Qaidam Basin, the reduction rate is much lower than the effects of discontinuous faults. (2) The stress field in M-PC is dominant by N-S compression in the whole part of Tibet and Qiangtang Block, the forces in orthometric directions are very weak. This may show that plastic materials absorb the extensional forces in the south part of Qiangtang and Tibet Blocks. The 

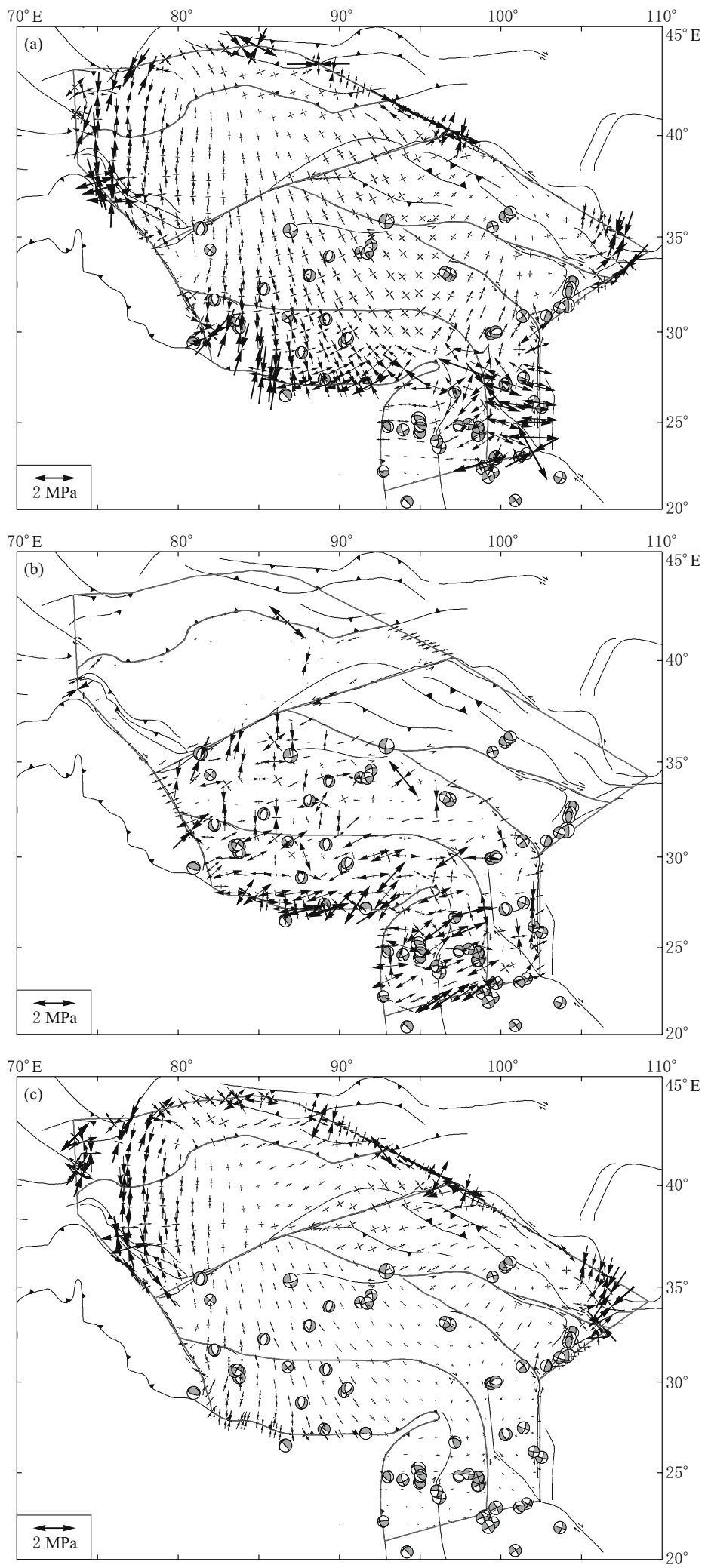

Figure 4 The stress fields of three models and the focal mechanisms of $M \geq 6.0$ earthquakes inside Tibetan Plateau occurred between 1976 and 2010. (a) Stress field of M-EC; (b) Stress field of M-ET; (c) Stress field of M-PC. The beachballs are the focal mechanisms of the $M \geq 6.0$ earthquakes. 
$\mathrm{N}-\mathrm{S}$ trend rifts in these areas may be mainly caused by fault properties. (3) The stress field in the east part of Tibetan Plateau is very weak, thus, the lateral extrusion cannot be accelerated by plastic materials, arguing that the fault strike slip is more important for driving the mass flow.

\subsubsection{Relationship of earthquake focal mecha- nisms and stress field}

In order to analyze the relationship between the stress field and the seismogenic structures, we collecte focal mechanisms of moderate to strong earthquakes inside Tibetan Plateau provided by Harvard CMT project. All of the earthquakes occurred between 1976 and 2010, with magnitudes equal to or larger than M6.0. Compared the patterns of focal mechanisms and the stress fields beween the M-EC, M-ET and M-PC models, several characteristics can be found. (1) In the middle and western part of Qiangtang the Lhasa blocks, there are many N-S trend normal fault earthquakes, which is inconsistent with the stress field of the continuous models of M-EC and M-PC. While in the discontinuous model M-ET, in these areas, the stress field is dominant with E-W extensional force, the focal mechanism and the stress field are in relatively good consistence. (2) In the north part of the Qiangtang block, focal mechanisms are dominant with strike-slip components. All of the three kinds of stress fields have compression and extension forces, but the directions of the forces are different; in the M-EC, the directions of compress are mainly along northwest to southeast, while the stress exhibited by the focal mechanism show a dominant direction of NE to SW, conjugated with extensional stress in NE to SE, which conflicts with the stress field of the continuous models, but in a relatively better consistence with that of the M-ET model. This kind of discrepancy shows that the stress field near the major active faults, including the Kunlun fault and the Altyn fault, the effects of fault movement on the stress field are even stronger than that inside the Tibetan Plateau. (3) In the eastern part of the Tibetan Plateau, focal mechanisms are quite complex, including E-W normal fault earthquakes, N-S normal fault earthquakes, and strikeslip fault earthquakes. None of the stress fields of our three models can fit the focal mechanisms in this area. This is due to the following reasons, the first one is that there are many active faults located in this areas, which makes the stress field very complex, our simplified numerical models cannot simulate such kind of complex structure; secondly, this area is the boundary between the Tibetan Plateau, the Sichuan Basin, and the South
China block, thus, the gravity potential may play an important role in this area (Yang et al., 2003).

Although our numerical models cannot fit the focal mechanisms very well, the overall fitness between the discontinuous model result and the focal mechanisms are acceptable, which shows that the properties of the discontinuous faults play a significant role in the seismicity and the stress field of the inner part and the north boundary of the Tibetan Plateau.

\section{Discussion and conclusions}

In this article, we build three kinds of finite element models and simulate deformation and stress fields of Tibetan Plateau, and then we compare the simulated results with GPS observation data. At the same time, we analyze the effects of active faults and material properties on the present stress field and movement pattern of Tibetan Plateau.

In summary, the effects of material properties and active faults on deformation and stress fields of Tibetan can be concluded in following aspects.

1) The deformation in short time scale can be well described by elastic models. The simulated velocities of continuous elastic model M-EC are in good consistent with GPS observations, provided only some misfits at the neighborhood of active faults. When we further consider the effects of discontinuous movement, the simulated velocity field can fit the observations very well.

2) Discontinuous fault movement does enhance the eastward flow of Tibetan Plateau, while plastic material does not. From the simulation result, we know that in the east part of Tibetan Plateau, when considering the discontinuous movement of fault, the E-W velocity will greatly increase in the plateau, and the components of E-W velocities are closer to GPS observations than those of M-EC model. However, the deformation field of continuous plastic model is almost the same as that of the continuous elastic model.

3) Discontinuous fault movement permits the velocity abrupt changes between different tectonic blocks while plastic material does not. From Figure 3b we can find in the two sides of active faults, such as Jiali fault, the velocities have big difference. This kind of velocity discontinuity is mainly caused by slip movement of fault, because in the discontinuous elastic model we can clearly find this kind of phenomenon while in continuous models, whatever elastic or plastic model, there is no velocity jump between blocks.

4) Discontinuous fault movement and plastic mate- 
rial can reduce the stress amplitude of Tibetan Plateau, but their stress fields are quite different. Without the effect of active fault, stress field of Tibetan Plateau is mainly controlled by the driving force of Indian Plate, and the blocking force of stable tectonic structure. This kind of simulated stress filed is quite different from the observed stress field. The discrepancy shows that the stress field is not only controlled by N-S driving force, other kinds of mechanisms also play important role on it. Discontinuous contact model (M-ET) strongly reduces this kind of discrepancy. In this model, the E-W extensional force is the biggest principle stress in middle part of Tibetan Plateau, which is much more consistent with the real case. Furthermore, in M-ET model, the stress fields in Tarim Basin, Qaidam Basin, SongpanGanzi Block are quite small, this may implicit that the faults movements absorb much of the shortening of Tibetan Plateau caused by the Indian Plate collision, and the faults convert the stress field from N-S compress to E-W extensional stress so that pull the crustal mass in Tibetan Plateau to move eastward and reduce the stress field far from the collision zone. The stress field in the plastic model M-PC is also reduced by the yield stress of Qiangtang Block and Tibet Plateau, but the stress pattern is quite different from M-ET. Compared M-EC with M-PC, the E-W extensional forces are reduced in Qiangtang and Tibet Block so that only N-S and near N-S compressed forces exist. This may implicit that the anelastic properties are the main mechanism for distributed shortening and thickening of the Tibetan Plateau.

$5)$ Both the material properties and the fault movement control the seismicity pattern in the main seismogenic belts of Tibetan Plateau, but the effect of fault is stronger. Figures $4 \mathrm{a}$ and $4 \mathrm{c}$ show that the stress field of nonlinear material model is quite different from elastic model, which means that material properties have important effects on the stress filed. As we know that the stress field controls the seismic activities, so material can play important role on the seismicity pattern in the interior of a block. On the other hand, fault effect controls the earthquake distribution and focal mechanism near the active fault because of the slip movement between the two sides of fault. In most cases, focal mechanism of earthquake can tell us the geometry character of fault. For this reason, studying on mechanic characteristics and the nature of fault will help us to evaluate seismicity pattern and predict earthquakes in Tibetan Plateau and its surrounding areas.

In conclusion, fault movement and material prop- erties have important effects on the evolution, movement, deformation and seismicity of Tibetan Plateau. In order to get a clear image of evolution process and the movement status, we must pay more attention to the dynamic character of the main active faults and the materials in the tectonic blocks.

Choosing reasonable materials is critically important for the success of numerical modeling. If we want to research the present kinematics of Tibet, elastic models should be a good choice, because it can provide accurate deformation filed and much easier computation. That's why interpolate method can provide good movement image of Tibetan Plateau (e.g, Haines and Holt, 1993; Holt et al., 2000). However, if we want to simulate the long term evolution process, elastic material may not be a good choice for some highly deformed tectonic blocks. In these areas nonlinear materials should be selected because they can absorb the big strain and accumulate unrecoverable deformation, this is the most important factor for crustal thickening (e.g., Royden et al., 2008; Wang et al., 2007).

Fault movement is also a key point to the studies of tectonics of Tibetan Plateau. If we want to study the crustal shortening and lateral extrusion of Tibetan Plateau, the effect of discontinuous fault movement must be considered, because it increases the lateral mass extrusion and converts the stress field of Qiangtang and Tibet blocks from N-S compression to E-W extension. Furthermore, study on the detail interaction of fault$\mathrm{s}$ and blocks will give us important information about seismogenic structures. Tibetan Plateau and its adjacent areas are highly actively seismic regions, more than half of the big earthquakes in China happened in these areas, in recent period there are several destructive earthquakes happened in these areas, including May 12, 2008 Wenchuan, Sichuan $M_{\mathrm{S}} 8.0$ earthquake. Geological surveys and seismological researches show that the main shock and the strong aftershocks of Wenchuan earthquakes are prone to happening on the faults those locate in areas with strong strength rocks or at the boundary of strong and weak tectonic zones (Zheng, 2009; CAG, 2008). So studying on the stress field, fault movemen$\mathrm{t}$ and the mechanic properties of the materials in the fault zones may help us to answer seismogenic mechanism and evaluate the future.

The average elevation of Tibetan Plateau is more than $4000 \mathrm{~m}$, which will also produce huge gravity potential effect. Undoubted the gravity potential will play an important role on the movement and evolvement of Tibetan Plateau. Liu and Yang (2003) found that the 
gravity potential is an important reason for eastern flow of Tibetan Plateau by analyzing the Quaternary velocity field of Tibetan Plateau. England and Molnar (2005) found the direction of horizontal principle stress axis is consistent with the gradient direction of topography, which also shows the gravity potential strongly affects the deformation of eastern Asian continent (e.g., Flesh et al., 2001; England and Monlar, 1997). In future work we will consider the gravity potential and try to get a more realistic dynamic process for Tibetan Plateau and its surrounding areas.

Acknowledgements We thank the Open Laboratory of Mechanics in USTC for their kindness to permit us to use the ANSYS license. We show our respect to Professor Sidao Ni in University of Science and Technology of China for his scientific directions. This work is jointly supported by Chinese Academy of Sciences (Nos.KZCX2-YW-116 and KZCX2-YW-142), National Natural Science Foundation of China (Nos.40974034 and 40064004). All of the figures are dawn by GMT software.

\section{References}

Avouac J P and Tapponnier P (1993). Kinematics model of active deformation in Central Asia. Geophys Res Lett 20: $895-898$.

Chinese Academy of Geology (CAG) (2008). Atlas of Wenchuan $M_{\mathrm{S}} 8.0$ Earthquake. Report of Wenchuan Expert Committee.

Ding Z F, He Z Q, Wu J P and Sun W G (2001). Research on the 3-D seismic velocity structures in Qinghai-Xizang Plateau. Earthquake Research in China 17(2): 202-209.

Ding Z Y, Yang Y Q, Yao Z X and Zhang G H (2001). A think-skinned collisional model for the Taiwan orogency. Tectonophysics 332: 321-331.

England P and Molnar P (1990). Right-lateral shear and rotation as the explanation for strike slip faulting in eastern Tibet. Nature 344: 140-142.

England P and Molnar P (1997). Active deformation of Asia: From kinematics to dynamics. Science 278: 647-650.

England P and Molnar P (2005). Late Quaternary to decadal velocity fields in Asia. J Geophys Res 110: B12401, doi: 10.1029/2004JB003541.

Flesch L M, Haines A J and Holt W E (2001). Dynamics of the India-Eurasia collision zone. J Geophys Res 106(B8): $16435-16460$.

Fu R S, Li L G, Huang J H and Xu Y M (1999). Threestep model of the Qinhai-Xizang Plateau uplift. Chinese $J$ Geophys 42(5): 610-616 (in Chinese with English abstract).

Haines A J and Holt W E (1993). A procedure for obtain- ing the complete horizontal motions within zones of distributed deformation from the inversion of strain rates data. J Geophys Res 98(B7): 12 057-12 082.

Holt W E, Chamot-Rooke N, Le Picheon X, Haines A J and Tu B S (2000). Velocity field in Asia inferred from Quaternary fault slip rates and Global Positioning System observations. J Geophys Res 105(B5): 19 185-19 209.

Houseman G and England P (1993). Crustal thickening versus lateral expulsion in the Indian-Asian continental collision. J Geophys Res 98(B7): 12 233-12 249.

Houseman G and England P (1996). A lithospheric thickening model for the Indo-Asian collision. In: Yin A and Harrison T M eds. The Tectonic Evolution of Asia. Cambridge University Press, New York, 3-17.

Kong X H and Bird P (1996). Neotectonics of Asia: Thinshell, finite element models with faults. In: Yin A and Harrison T M eds. The Tectonic Evolution of Asia. Cambridge University Press, New York, 18-35.

Lin A M, Fu B H, Guo J M, Zeng Q L, Dang G M, He W G and Zhao Y (2001). Co-seismic strike-slip and rupture length produced by the $2001 M_{\mathrm{S}} 8.1$ central Kunlun earthquake. Science 296: 2015-2017.

Liu M and Yang Y (2003). Extensional collapse of the Tibetan Plateau: Results of three-dimensional finite element modeling. J Geophys Res 108(B8): 2361, doi: 10.1029/2002JB002248.

Molnar P and England P (1990). Late Cenozoic uplift of mountain ranges and global climate change: Chicken or egg? Nature 346: 29-34.

Molnar P, England P and Martinod J (1993). Mantle dynamics, uplift of the Tibetan Plateau and the Indian Monsoon. Review of Geophysics 31(4): 357-396.

Molnar P and Tapponnier P (1975). Cenozoic tectonics of Asia: Effects of continental collision. Science 189: 419426.

Peltzer G and Saucier F (1996). Present day kinematics of Asia derived from geologic fault rates. J Geophys Res 101: $27943-27956$.

Peltzer G and Tapponnier P (1988). Formation and evolution of strike-slip faults, rifts and basins during the IndiaAsia collision: An experimental approach. J Geophys Res 93: $15085-15117$.

Peltzer G, Tapponnier P and Armijo R (1989). Magnitude of Late-Quaternary lefe-lateral displacements along the north edge of Tibet. Science 246: 1285-1 289.

Royden L H (1996). Coupling and decoupling of crust and mantle in convergent orogens: Implications for strain partitioning in the crust. J Geophys Res 101: 17679 17705.

Royden L H, Burchfiel B C and van de Hilst R D (2008). The geological evolution of the Tibetan Plateau. Science 321: $1054-1058$.

Royden L H, Burchfiel B C, King R W, Wang E, Chen Z L, Shen F and Liu Y P (1997). Surface deformation and 
lower crustal flow in eastern Tibet. Science 276: 788790 .

Sella G F, Dixon T H and Mao A (2002). Revel: A model for recent plate velocities from space geodesy. $J$ Geophys Res 107(B4), doi:10.1029/2000JB000033.

Shen F, Royden L H and Burchfiel B C (2001a). Large-scale crustal deformation of the Tibetan Plateau. J Geophys Res 106(B4): 6 793-6816.

Shen Z K, Wang M, Li Y X, Jackson D D, Yin A, Dong D $\mathrm{N}$ and Fang P (2001b). Crustal deformation along the Altyn Tagh fault system, western China, from GPS. $J$ Geophys Res 106(B12): $30607-30621$.

Stone R (2008). An unpredictably violent fault. Science 320 : 1578-1580.

Su W, Peng Y J, Zheng Y J and Huang Z X (2002). Crust and upper mantle shear velocity structure beneath the Tibetan Plateau and adjacent areas. Acta Geoscientia Sinica 23(3): 193-200.

Tapponnier P and Molnar P (1977). Active faulting and tectonics of China. J Geophys Res 82: 2905-2 930.

Tapponnier P and Molnar P (1979). Active faulting and Cenozoic tectonics of Tien Shan, Mongolia and Baykal regions. J Geophys Res 84: 3425-3 459.

Tapponnier P, Meyer B, Avouac J P, Peltzer G, Gaudemer Y, Guo S M, Xiang H F, Yin K L, Chen Z T, Cai S H and Dai H G (1990). Active thrusting and folding in the Qilian Shan, and decoupling between upper crust and mantle in northeastern Tibet. Earth Planet Sci Lett 97: 382-403.

Tapponnier P, Peltzer G and Armijo R (1986). On the mechanics of the collision between India and Asia. In: Coward M P and Ries A C eds. Collision Tectonics. Geol Soc Lond Spec Publ 19: 115-157.

Tapponnier P, Xu Z Q, Roger F, Meyer B, Meyer B, Arnaud N, Wittlinger G and Yang J S (2001). Oblique stepwise rise and growth of the Tibetan Plateau. Science 294: 1671-1677.

Wang C Y, Han W B, Lou H and Chan W W (2007). Crustal structure beneath the eastern margin of the Tibetan Plateau and its tectonic implications. J Geophys Res 112: B07307, doi: 10.1029/2005JB003873.

Wang Q, Zhang P Z, Freymueller J T, Bilham R, Larson K
M, Lai X A, You X Z, Niu Z J, Wu J C, Li Y X, Liu J N, Yang Z Q and Chen Q Z (2001). Present-day deformation in China constrained by Global Positioning System measurements. Science 294: 574-577.

Wang Z M (2001). Analysis of discontinuous deformation and modern crustal movement. [PhD Dissertation]. Wuhan University, Wuhan.

Xiong X, Park P H, Zheng Y, Hus H and Han U (2003). Present-day slip-rate of Altyn Tagh Fault: Numerical result constrained by GPS data. Earth Planet Space 55: 509-514.

Xu Z H, Wang S Y, Huang Y R and Gao A J (1989). Analysis of Chinese continental tectonic stress field by massive earthquake data. Chinese J Geophys 32(6): 346-354 (in Chinese with English abstract).

Yao H, Beghein C and van der Hilst R D (2008). Surface wave array tomography in SE Tibet from ambient seismic noise and two-station analysis II. Crustal and uppermantle structure. Geophys J Int doi:10.1111/j.1365246X.2007.03696.x

Yao H, Van der Hilst R D and de Hoop MV (2006). Surfacewave array tomography in SE Tibet from ambient seismic noise and two-station analysis I. Phase velocity maps. Geophys J Int 166: 732-744.

Yin A and Harrison T M (2000). Geological evolution of the Himalayan-Tibetan Orogen. Annual Review of Earth Planetary Sciences 28: 211-280.

Zheng Y, Chen Y, Fu R S and Xue T X (2007), Simulation of the effects of faults movement on stress and deformation fields of Tibetan Plateau by discrete movement modes. Chinese J Geophys 50(5): 122-132 (in Chinese with English abstract).

Zheng Y, Fu R S and Xiong X (2006). Dynamic simulation of lithospheric evolution from the modern China mainland and its surrounding areas. Chinese $J$ Geophys 49(2): 415-427 (in Chinese with English abstract).

Zheng Y, Ma H-S, Lü J, Ni S D, Li Y C and Wei S J (2009). Source mechanism of strong aftershocks $\left(M_{r m S} \geq 5.6\right)$ of the 2008/05/12 Wenchuan earthquake and the implication for seismotectonics. Science in China (Series D) 52(6): 739-753. 